\title{
CFD Engine Applications at FIAT Research Centre
}

\author{
M. G. Lisbona ${ }^{1}$ \\ 1 Fluid Dynamics Dept., Engine Division, Fiat Research Centre, Strada Torino 50, Orbassano - TO - Italy \\ e-mail: m.lisbona@crf.it
}

\begin{abstract}
Résumé - Applications de la modélisation 3D au FIAT Research Centre - Cet article présente la simulation 3D du cycle complet du moteur $2400 \mathrm{~cm}^{3}$ JTD $10 \mathrm{~V}$ de l'Alfa Romeo 156. L'analyse de la phase d'admission a suivi une procédure habituellement utilisée pour les moteurs à essence. L'analyse du spray et de la combustion au régime choisi de $3500 \mathrm{tr} / \mathrm{mn}$ et 13 bar de PMI se compare raisonnablement aux essais, mais indique qu'une meilleure description de la phase initiale de la combustion est nécessaire. La simulation de la phase d'échappement a requis une grande attention quant à la spécification du champ initial et des conditions aux limites. On étudie ici les caractéristiques de l'écoulement à deux instants de cycles correspondant à des maxima de débits à l'échappement.
\end{abstract}

\begin{abstract}
CFD Engine Applications at FIAT Research Centre - The CFD (computer fluid dynamic) simulation of the complete engine cycle of the $2400 \mathrm{~cm}^{3}$ JTD $10 \mathrm{~V}$ engine for the Alfa Romeo 156 is presented. The intake stroke analysis has followed a procedure usually applied at CRF for gasoline engines. Spray and combustion analysis at the selected operating condition of 3500 tr/min and 13 bar BMEP (brake mean effective pressure) has given results in fair agreement with the experimental data, but revealed the need of more accurate models for the initial phase of combustion. Finally, the simulation of the exhaust phase has required great care in the set-up of the initial field and boundary conditions. Flow field characteristics are discussed at two crank angles, corresponding to peak values of the exhaust mass flow rate.
\end{abstract}

\section{INTRODUCTION}

During the development of a new engine and often before the construction of the first prototypes, CFD analysis is nowadays applied in verifying and optimising the engine design. The ease of setting-up the analysis and the accuracy of the results are well known for some areas of investigation such as coolant circuits inside the engine block and head and intake and exhaust manifolds.

Much more complex is the in-cylinder flow analysis and especially, as expected, the spray and combustion phenomena simulations either for gasoline or Diesel engine. The CFD approach is constantly applied at CRF for the analysis of the intake phase and homogeneous combustion of the new gasoline engines [1,2]. A step forward has been made recently. The paper presents the first attempt in simulating the complete engine cycle for the $2400 \mathrm{~cm}^{3}$ JTD $10 \mathrm{~V}$ engine for the Alfa Romeo 156.
The engine has the following characteristics:

- unit displacement $\quad 480 \mathrm{~cm}^{3}$

- bore $\quad 82 \mathrm{~mm}$

- stroke $\quad 90.4 \mathrm{~mm}$

- intake valve timing $\quad 0 / 32$ degrees c.a. (v. lift $0.5 \mathrm{~mm}$ )

- exhaust valve timing $32 / 0$ degrees c.a. (v. lift $0.5 \mathrm{~mm}$ )

- maximum valve

lift int./exh. $\quad 8.5 \mathrm{~mm}$

- compression ratio 18.4 .

The selected operating point is $3500 \mathrm{tr} / \mathrm{min}$ and $13 \mathrm{bar}$ BMEP. The computational grid is shown in Figure 1 and it contains about 92000 computational cells. It has been generated with a semi-automatic software for port meshing together with a good experience from the user. This part of the set-up has been greatly reduced, but still requires about two weeks of tedious work. During the induction phase the exhaust port is detached from the combustion chamber and the same approach is followed for the exhaust phase; the mesh in the cylinder region is stretched according to the 


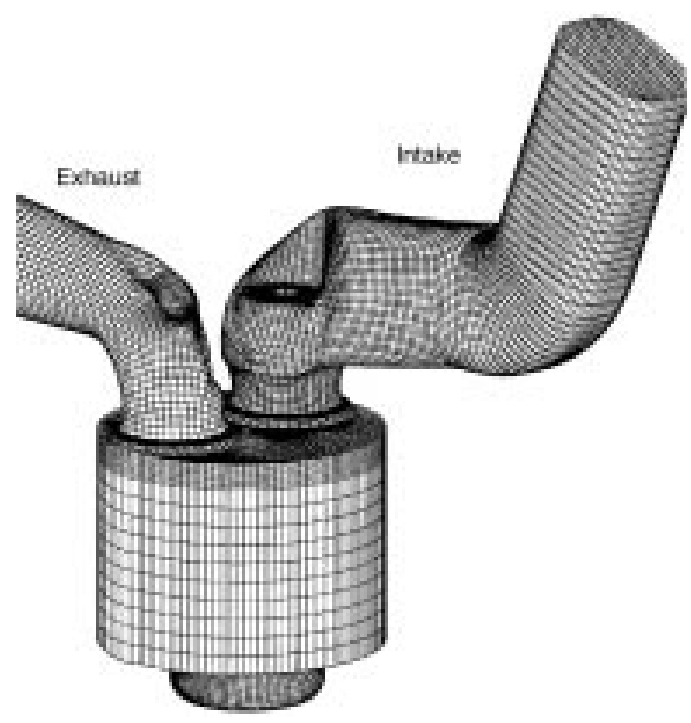

Figure 1

Computational mesh.

valve and piston motion. For the open valve periods the Star code from Computational Dynamics Ltd. has been used, while for compression, injection and combustion the Speed code, has been applied developed, during the Idea and Idea Effect European projects for Eucar.

\section{INTAKE PHASE SIMULATION}

The simulation starts at TDC (top dead center) with a valve lift of $0.5 \mathrm{~mm}$ with the initial and boundary conditions taken from the corresponding one-dimensional analysis performed with an in-house code. It should be pointed out that the 1D simulation requires as input the complete intake and exhaust system geometry that, at a very preliminary stage of development, could be taken from similar engines. Furthermore, the discharge coefficients of the intake and exhaust ports are usually taken from measurements of models made with the rapid prototyping technique.

The future integration during run-time between the 1D and 3D analysis will reduce the over-all time requirement for both types of analysis.

Results are usually discussed in terms of global valuesswirl ratio inside the cylinder during induction and at valve closure-and local features of the flow field in the port and valve region. For this application, interest was focused on the performance of the helical port, because due to the presence of a coolant passage, its design had been slightly restricted close to the valve seat.

As global evaluation of the port design, the instantaneous trend and the IVC (instant valve closure) values of the mass trapped in the cylinder and its swirl ratio are used; this helical port gives a swirl ratio of 2.1 at valve closure.
Going into details, in Figure 2, swirl, axial and radial velocities in the middle of the valve curtain at 40 degrees c.a. and 100 degrees c.a. ATDC (after top dead center) are shown at half and maximum valve lift conditions, respectively. At the lower valve lift, radial and axial velocities are uniform around the valve, while the swirl component is low; the port is more effective for flow capacity. At the higher valve lift, the swirl component has increased, but due to the port design, the flow is less driven in the valve curtain region under the port, causing a relative decrease of flow capacity. A more detailed explanation of this behaviour is shown in Figure 3, depicting the velocity field inside the port at several crosssections parallel to the cylinder head plane.
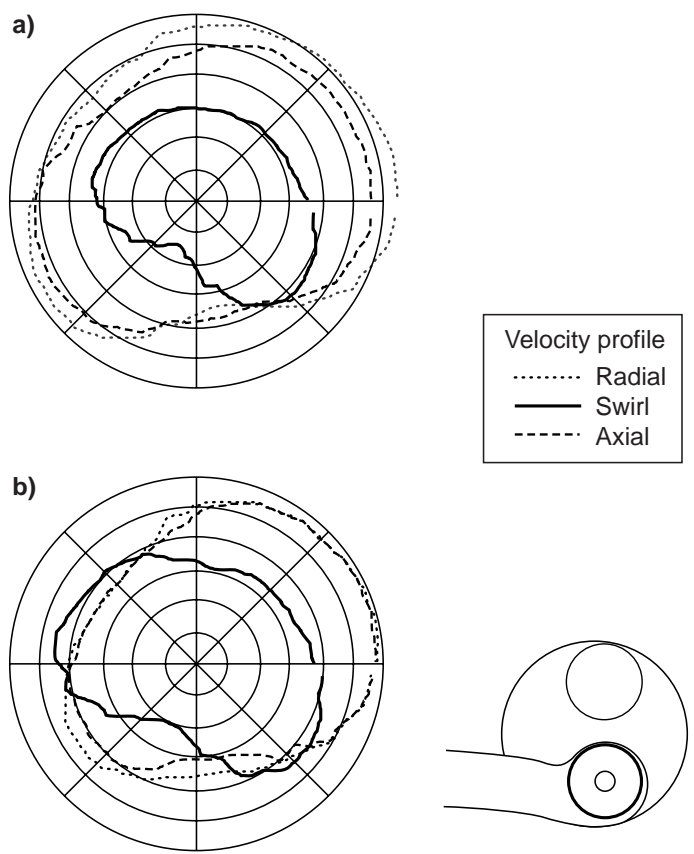

Figure 2

Velocity profiles at the valve curtain.

a) at 40 degrees c.a.; b) at 100 degrees c.a. ATDC.

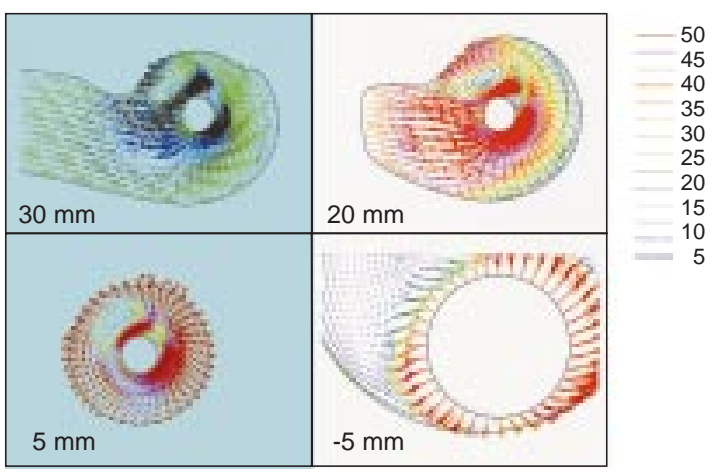

Figure 3

Velocity field at 100 degrees c.a.

Cross sections at various distances from cylinder head. 
Particle tracking, results animation can be quickly performed and have a great potential in helping the engine designers in understanding the $3 \mathrm{D}$ flow field results.

\section{SPRAY AND COMBUSTION}

The simulation has continued after IVC for the in-cylinder region, but using a more detailed mesh, especially inside the bowl. The particular engine is equipped with a Common Rail injection system and 5 holes x $0.18 \mathrm{~mm}$ diameter nozzle injectors. The injection pressure for this operating condition is 1350 bar and the injected fuel quantity is about $50 \mathrm{~mm}^{3} /$ stroke. Many authors have extended atomisation and break-up models to high pressure injection sprays $[3,4,5]$ and following their results, some modifications have been included in the Speed code. For the combustion simulation a 4 step reduced kinetics scheme from [6] and the well-known Magnussen combustion model have been used.

Regarding injection input data, it is well-known that results are strongly dependent on injected quantity and phasing. Problems and uncertainties arise because the available information coming from the engine test cells often concerns only the commands given by the ECU (electronic computer unit). So, it is necessary to reproduce on an injector test-rig the same electronic signal and measure the actual injection rate. The shift between ECU commands (start and injection period) and injector actuation is not negligible and the injection law is far from being of rectangular shape. Since atomisation and break-up models are based on injection velocity, this procedure was repeated for each operating condition calculated.

For this application, injection starts 9 degrees c.a. BTDC (before top dead center) and lasts $1310 \mu \mathrm{s}$. The numerical and experimental pressure cycles are compared in Figure 4

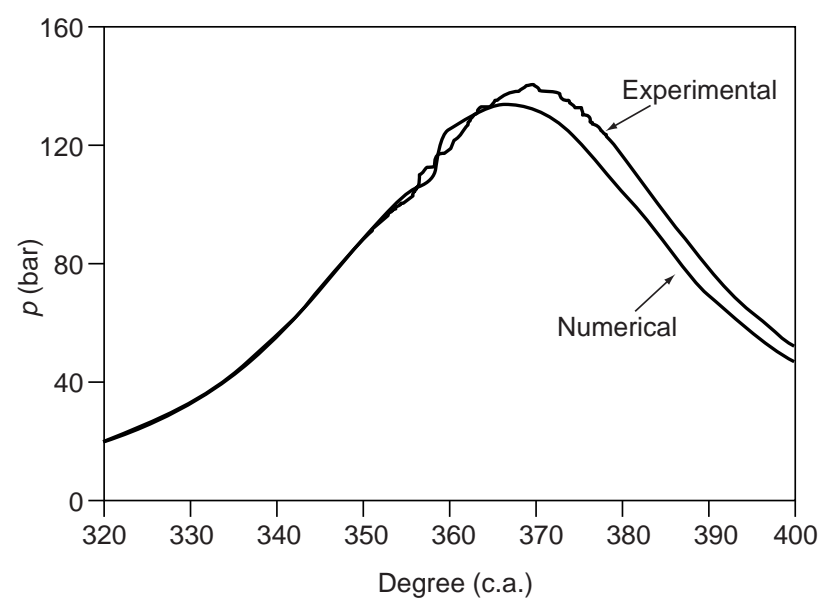

Figure 4

Comparison of pressure cycles. and the agreement is fair although during the early stage of combustion needs to be improved.

Looking at the three-dimensional results, in Figure 5 the evolution of the gas radial and axial velocity components in the combustion chamber are presented. At 351 degrees c.a. squish velocities are around $35-40 \mathrm{~m} / \mathrm{s}$ and the swirl component about $55-60 \mathrm{~m} / \mathrm{s}$, maximum value for component around $55-60 \mathrm{~m} / \mathrm{s}$ with maxima for both components located at the bowl lip.
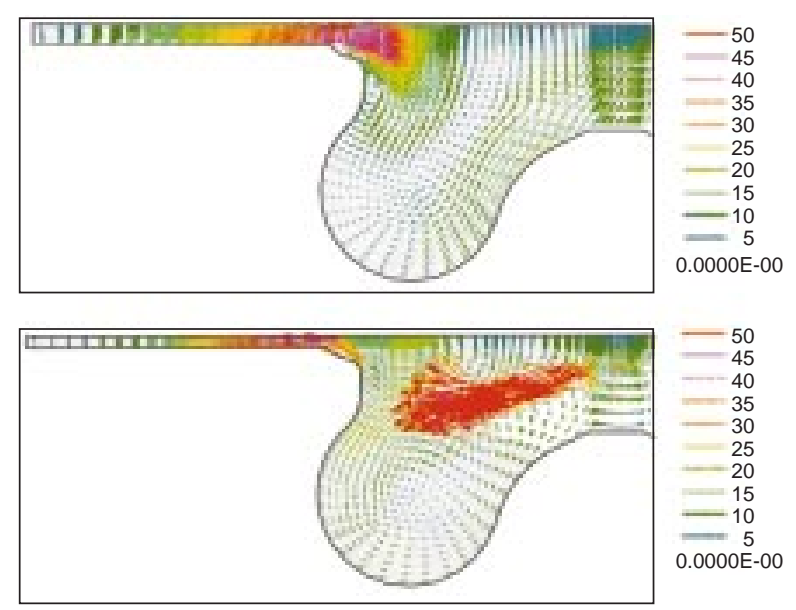

Figure 5

Radial and axial velocity components at 351 degrees c.a. (top) and at TDC (bottom).

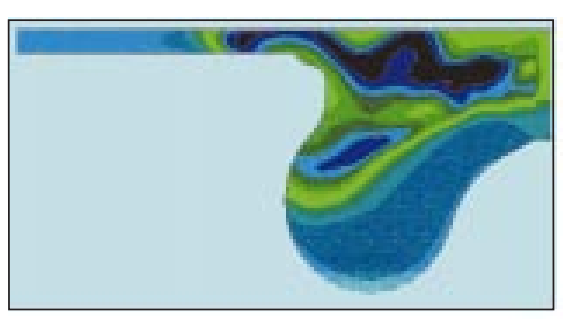

Temperature absolute (K) Time $=370.000$ Local $\mathrm{MX}=3287$ Local $\mathrm{MN}=830.6$
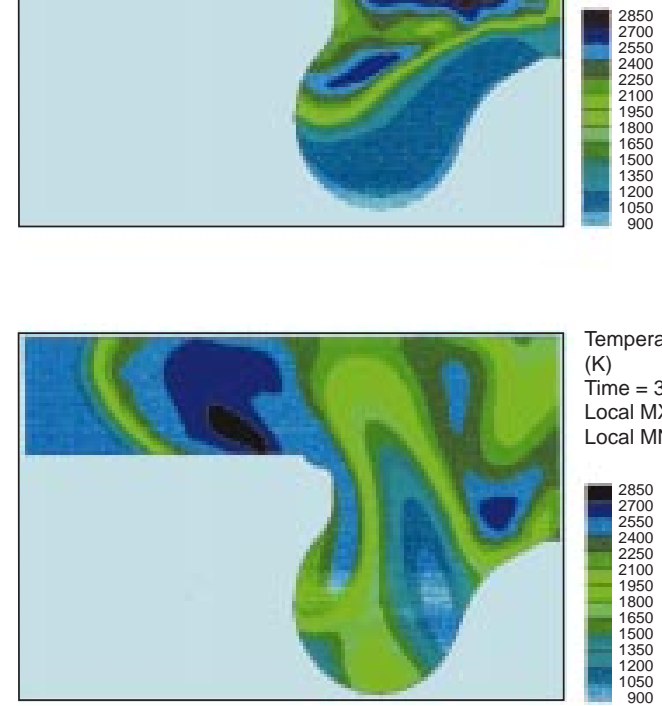

Temperature absolute (K) Time $=390.000$ Local MX $=2840$ Local $\mathrm{MN}=705.7$

Figure 6

Temperature distribution at 370 degrees c.a. (top) and 390 degrees c.a. (bottom). 
At TDC, it is evident that the spray velocity is much higher than that of the flow field and its presence causes velocities in the squish region to be already directed outwards. This behaviour could also be seen in the temperature distribution; in Figure 6 at 370 degrees c.a. high temperatures are, as expected, in the bowl region, but also in the squish region where fuel vapour is transported. At 390 degrees c.a., when the in-cylinder pressure is strongly decreasing, combustion has still not reached the liner and the lower part of the bowl. Then, the temperature front continues propagating and becomes more uniform until the opening of the exhaust valve.

\section{EXHAUST PHASE SIMULATION}

This simulation has been extremely delicate. The initial condition for the cylinder region comes from the combustion simulation and the flow condition in the exhaust port and pipe has been taken again from the 1D analysis. The initial pressure drop across the valve is very high and has required a very small time-step to start the simulation resulting in considerably increased CPU time requirements. Furthermore, the exhaust pipe has been extended till the five-in-one junction where the time-dependent pressure boundary condition has been specified.

In Figure 7 the mass flow rate at the valve is compared with the $1 \mathrm{D}$ results analysis and clearly shows the spontaneous and forced exhaust phases.

At 150 degrees c.a. BTDC, Figure 8, the velocity field shows a sonic behaviour. It is worth noting that there is a nonuniform velocity distribution along the port cross section: the

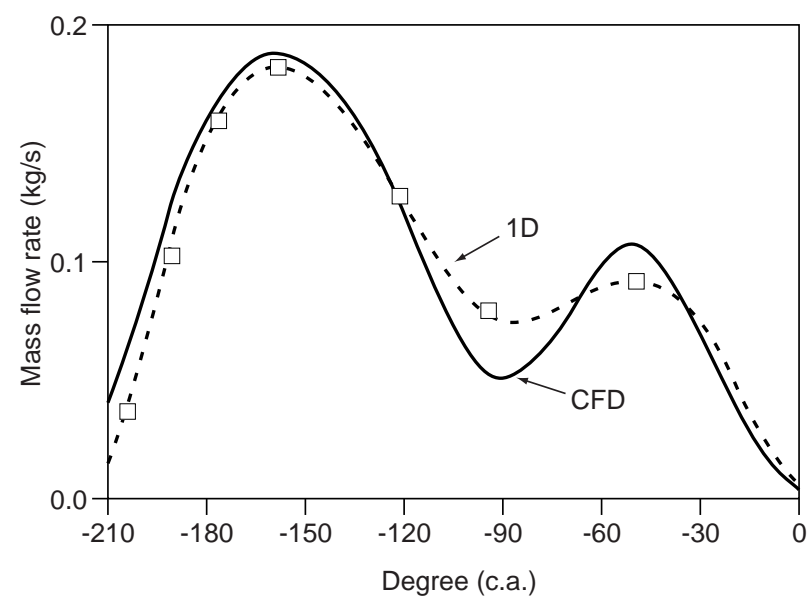

Figure 7

Mass flow rate during exhaust. hot flow is impinging on the upper part of the port, a region of high heat transfer, while in the lower part the flow is weak.

At 50 degrees c.a. BTDC velocities are lower with a more uniform distribution across the port. Design suggestions on flow and valve seat interaction and on port curvature could be easily deduced.

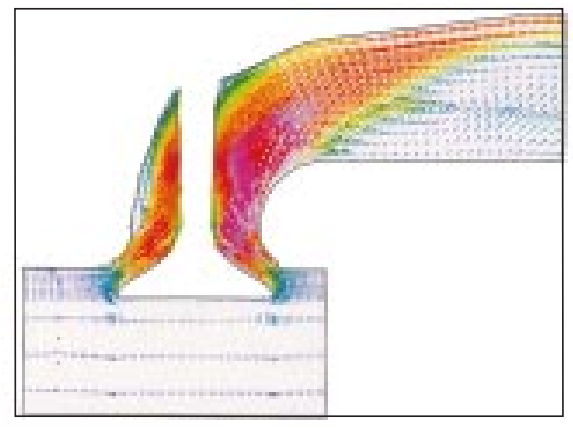

Velocity magnitude Time $=0,295235 \mathrm{E}-02$ Local MX $=564.3$ Local $\mathrm{MN}=0.5391$

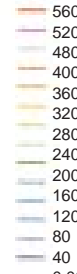

560
520
480
400
360
320
280
240
200
160
120
80
40

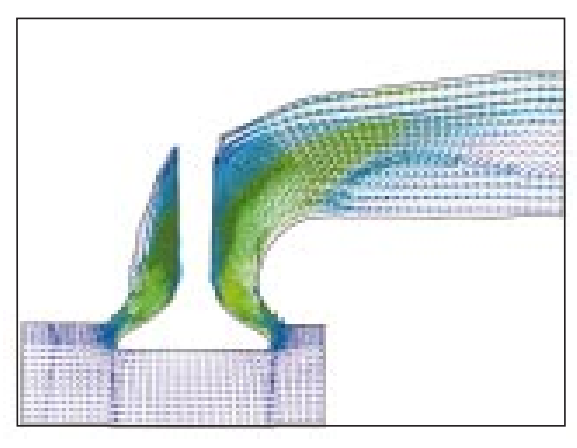

Velocity magnitude $\mathrm{m} / \mathrm{s}$

Time $=0,771374 \mathrm{E}-02$ Local $M X=314.7$ Local MN $=0.3633$

Figure 8

Velocity field at 150 degrees c.a. (top) and 50 degrees c.a. (bottom) before TDC.

\section{CONCLUSION}

Results of the simulation of the complete engine cycle for the $2400 \mathrm{~cm}^{3}$ JTD engine have been presented together with "a list" of the required input data for each phase considered.

Regarding the induction stroke, a well-known methodology has been applied and possible developments would concern the integration with the $1 \mathrm{D}$ analysis and the extension to 4-valve per cylinder engines.

Spray and combustion analysis, especially for high pressure injection systems, are in an early stage of application in the industrial environment. Engineers are mainly interested into low load and rpm conditions where pilot injection and EGR are used, but for these applications modelling work is still required. 
The analysis has been extended to the exhaust stroke and results have shown significant three dimensional features of the flow field in the exhaust port.

\section{REFERENCES}

1 Lisbona, M.G and, Vafidis C. (1997) Adoption of CFD in the Engine Design Process: Present and Future. ATA Congress, The Virtual Automobile and the Role of Experimentation, Florence.

2 Ballario, V., Lisbona, M.G., Piana, A. and Mascellini, R.M. (1997) CFD Simulation of Induction, Compression and Combustion of the FIAT Torque $1.6116 \mathrm{~V}$ Gasoline Engine. Internal Combustion Engines: Experiments and Modelling, Capri.
3 Patterson, M., Kong, S., Hampson, G. and Reitz, R. (1994) Modeling The Effects of Fuel Injection Characteristics on Diesel Engine Soot and Nox Emissions. SAE Technical Paper No. 940523.

4 Su, T., Patterson, M., Reitz, R. and Farrell, P. (1996) Experimental and Numerical Studies of High Pressure multiple Injection Sprays. SAE Technical Paper No. 960861.

5 Habchi, C., Verhoeven, D., Huynh Huu, C., Lambert, L., Vanhemelryck, J. and Baritaud, T. (1997) Modeling Atomization and Break Up in High Pressure Diesel Sprays. SAE Technical Paper No. 970881.

6 Mueller, U.C. and Peters, N. (1990) Development of Reduced Reaction Schemes for the Ignition of Diesel Fuels in a Non-premixed Turbulent Flow Field. IDEA Project, Periodic and Final Report.

Final manuscript received in March 1999 